\title{
IT PROFESSIONAL USERS AND VENDORS' PERCEPTIONS OF THE KEY FACTORS IN ADOPTING CLOUD-MANAGED NETWORKS TECHNOLOGY
}

\author{
Chalermpon Kesa, Robert Morris University, cxkst116@mail.rmu.edu \\ Peter Draus, Robert Morris University, draus@rmu.edu
}

\begin{abstract}
This study investigates the perceptions between IT professional users and vendors/resellers in term of the five key factors: complexity, compatibility, cost saving, security, and job performance for cloud-managed networks adoption, and seeks ranking of the importance of the factors. The findings indicate that IT professional users and vendors have different perceptions in all five factors, and ranking differently. Security factor was the least important factor when compared to the rest of other factors. This study provides important results that might help practitioners and academics in understanding the perceptions and the ranking of important factors, improve IT frameworks adoption, product development and marketing strategies, and enhance decision making of cloud-managed networks adoption.
\end{abstract}

Keywords: Technology acceptance model (TAM), Diffusion of Innovation theory (DOIT), Cloud Computing, Cloud-managed network, Virtualization, Perceptions

\section{INTRODUCTION}

Today, most organizations rely on Information technology (IT). IT leaders should adopt this trend because of the cost advantages of solid commodity products and services (Hoving, 2007). The top five IT and management concerns are as follows: (1) business productivity and cost reduction, (2) IT and business alignment, (3) business agility and speed to market, (4) business process re-engineering to reduce manual labor and costs, and (5) IT cost reduction such as IT budgets and staffs' salaries. Therefore, the most important objectives of IT should be concerned about IT cost reductions and productivity improvements (Luftman \& Ben-Zvi, 2009; Luftman et al., 2013).

Cloud computing helps to improve cost-saving and efficiency with a scalable network of sharing computing resources such as applications, networks, servers, and storages, which share from one locality into the cloud Internet (Boroujerdi \& Nazem, 2009). Internet is one of the driving force of cloud services and stimulates the demand for cloud-managed networking in addition to the draw of the cost advantages, less complexity, security, increased productivity and an easily managed IT network devices in the cloud. For example, Cisco Meraki, cloud-based managed network devices, an ease of setup without technical knowledge and using Web-based dash board (Middleton \& Potter, 2008). Cloud-managed networks seem to be the way forward for all and provide a scalable network infrastructure without network paraphernalia. Cloud-managed networks technology offer the benefit of reducing costs and the burden of providing the services of on-premised managed network devices such as Ethernet switches, wireless access points, routers, and firewall for setup, deploying, provisioning and monitoring (Cisco, 2016). This trend toward cloud-managed networks is typified by a range of products from Cisco, HP Aruba, Brocade, and Ruckus (Yap et al., 2009). IT cloud-managed networks addresses the key concerns of IT. However, without having a clear understanding of the perceptions of users' key factors in adopting cloud-managed network technology, IT will not be able to get the full advantage of such an innovation. There are no scholarly studies about the influential key factors in adopting cloud-managed networks and how IT users perceive the important factors of cloud-managed networks.

The purpose of this study is to investigate the perceptions between IT professional users and vendors/resellers on the key factors in adopting cloud-managed network products, and ranking of the important factors. The study explores five factors that include complexity, compatibility, cost saving, security, and job performance. Technology acceptance model (TAM), Diffusion of Innovation theory (DOIT), and other studies are used as guidelines to identify the key factors. 


\section{LITERATURE REVIEW}

The potential perception inconsistency regarding the risk between the client and vendor for IT outsourcing projects as a result there are some inconsistencies in perceived risk by the two parties: (1) clients regarded a lack of vendor commitment to the project and poor vendor selection criteria and process but vendors didn't; and (2) on the other hand, vendors perceived unclear requirements and lack of experience and expertise with project activities as significant risk but clients didn't (Liu \& Yuliani, 2016). Stakeholders may have different opinions regarding risk factors, and their opinion influences risk control planning (Keil, Tiwana \& Bush, 2002), therefore an inconsistent perception attracted the numbers of researchers' attention. In summary, IT project results in lower user satisfaction and lower quality of project outcome because of conflicting goals between clients and vendors (Gorla \& Somers, 2014). Based on a recent survey conducted by the Standish Group, about $75 \%$ of IT projects are cancelled before completion or are delivered over budget, behind schedule and with fewer features and functions than initially specified (Johnson et al, 2001). The Standish Group's figures indicate that the average IT project exceeds its budget by $90 \%$ and slips off its schedule by $120 \%$ (Keil, Tiwana \& Bush, 2002). So, the understanding of perceptions between users and vendors helps to improve product development strategy, to prioritize significant important and less concerns of the factors, and to be a better adoption technology. Network virtualization is being adopted in both telecommunications and the Internet as a key attribute for the next generation networking (Duan \& Vasilakos, 2012). Cloud networking (Cloud-based IT networking or cloud-managed networks) is a term describing networking resources accessed from a centralized third-party provider using Wide Area Networking (WAN) or Internet-based access technologies (SDxCentral, 2012).

Two theoretical models of technology adoption: Technology Acceptance Model (TAM) and Diffusion of Innovation (DOIT), are used as a guideline for identifying key influential factors on the adoption of cloud-managed networks in this study. Rogers (2003) stated that diffusion is the process by which an innovation is "communicated through certain channels over time among the members of a social system" (p. 6). He added that "diffusion is a special type of communication concerned with the spread of messages that are perceived as new ideas." One of the most widely applied and robust theoretical model in information systems (IS) is TAM (Davis, 1989; Venkatesh \& Davis, 1996; Gefen and Straub, 2000; Yu, Liu \& Yao, 2003).

Perceived usefulness and perceived ease of use are strong significant and positive relationship with users' intention to use cloud computing solutions (Trinh, 2014). Perceived usefulness is prospective user's subjective probability that using a specific application system will increase his or her job performance within an organizational (Davis, 1989).

Complexity of an innovation can act as a barrier to implementation of new technology; complexity factor is usually negatively affected (Premkumar \& Ramamurthy, 1995).

Cost saving is accessed by two items: installation cost and maintenance cost (Premkumar and Roberts, 1999). Therefore, cost may impact the adoption of cloud-managed networks technology.

Compatibility has been considered an essential factor for innovation adoption (Cooper and Zmud, 1990; Wang et al., 2010). The other factors are found crucial consideration keys to online success for online retailers such as pricing, customer support, cost-saving and conversions (McCloskey, 2004).

Security is one of the major issues which reduces the growth of cloud computing and complications with data privacy and data protection continue to ruin the market (Subashini \& Kavitha, 2011). Security module should cater to the issues arising from a directions of the cloud (Subashini \& Kavitha, 2011). The cloud network approaches provide basic reachability using dynamic or static IP addresses assigned to customer VMs, with basic firewall capabilities available and has the potential to save cost with less complexity (Theophilus, Aditya, Anees \& Sambit, 2011).

The integrative theoretical framework in Figure 1, is be used as a guide for the theoretical and empirical literature review of the key factors of cloud-managed networks adoption. Those factors are presented in the following theoretical framework: (1) complexity, (2) compatibility, (3) security, (4) job performance, and (5) cost saving. 


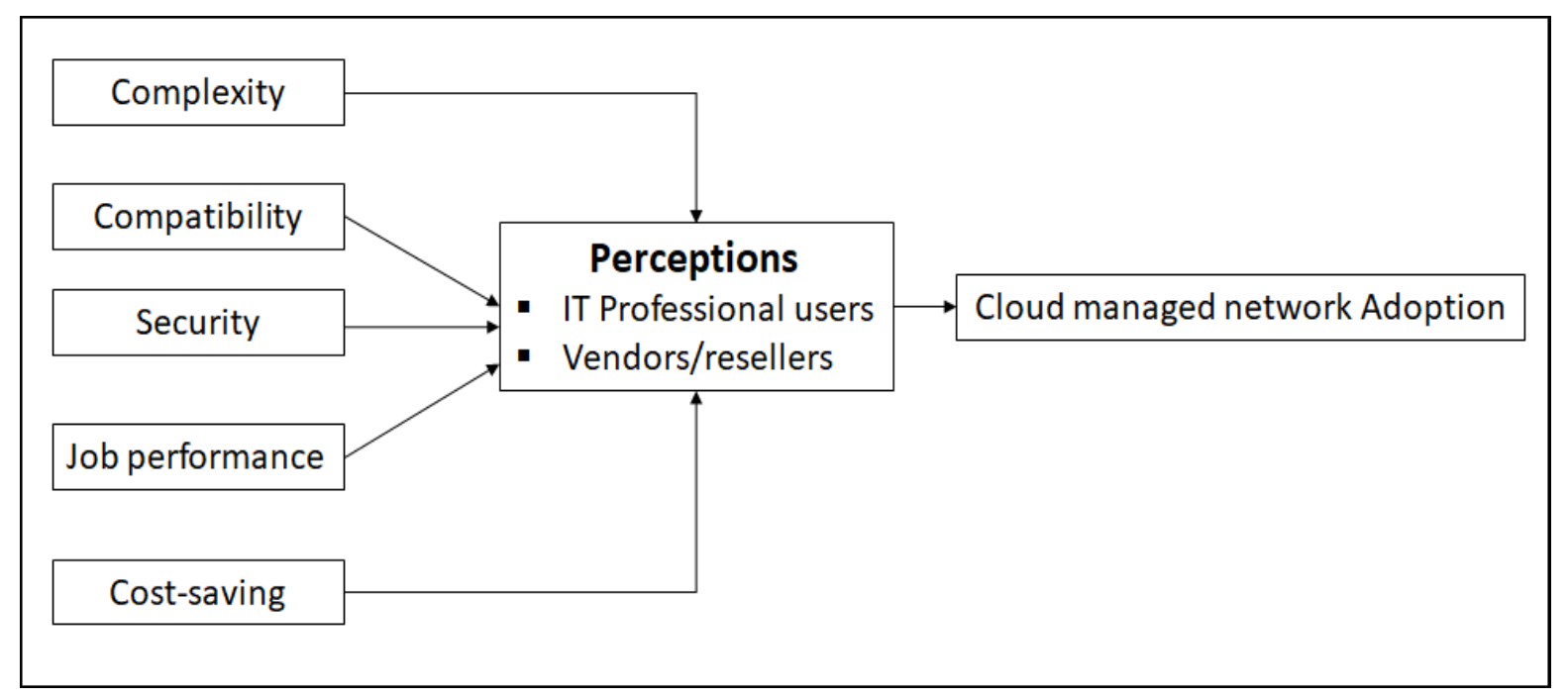

Figure 1. Theoretical framework

\section{RESEARCH QUESTION}

To accomplish the goal of this research, the study addresses the following research questions:

RQ1: What are the IT professional users and vendors' perceptions on the adoption of cloud managed networks in terms of complexity, compatibility, cost saving, security and job performance factors?

RQ2: What are the differences between the IT professional users and vendors' perceptions of the five factors?

RQ3: What is the ranking of the importance of five factors?

\section{METHODOLOGY}

Creswell (2009) argued that a quantitative study is the best research method when a person is trying to explain relationships among variables, rather than having an experimental correlational research design. To conduct the study, the quantitative approach is used in the form of an online survey instrument. The study employs web-based for administering surveys, which contains a blend of questions from the three survey instruments of TAM, DOIT, and other studies of cloud computing related technology adoption to cloud-managed networks: the ease of use and the usefulness factor questions of TAM; the complexity and the compatibility factor questions of DOIT; and the security and the cost savings factors of other previous studies. A pilot test is used to refine the test instrument and specific issues addressed including: question ambiguity, the refinement of the research protocol, and the confirmation of scale reliability (Van and Hundley, 2001). The series of closed-ended questions to find the perceptions between IT professional users and vendors on the five key factors of cloud-managed network adoption, the ranking important factors.

This study identified a group of people for selection, because they had some traits for this research. The population of this study consists of two groups for selection which are IT users and vendors. The first group was IT users who know about or have experience using a router, switch, Wi-Fi access point, or security firewall at their company or at home, for example, people who worked within IT networking areas such as network engineers, IT support, operations, managers, consultants, project managers, teachers, or students. The participants use either network devices or cloud-managed networks. The second group was vendors or resellers who sell cloud-managed network products, such as Cisco. The participants of these groups were salespersons, marketers, engineers, or work in customer support. Alfifi (2015) found that the sample size from previous studies of cloud computing adoption was between 70 to 150 participants. The Likert-type scale is used to measure the perception of IT professional users and 
vendors in terms of the five factors: complexity, compatibility, cost savings, security, and job performance. Using scale: $1=$ Strongly Disagree, $2=$ Disagree, $3=$ Neutral, $4=$ Agree, $5=$ Strongly Agree .

Data Collection. The study conducts the sample size of 235 participants, who work related to computer networks such as LAN, WAN, wireless, Wi-Fi or security firewalls, and cloud networking technology.

Data Analysis. The overall statistical finding of demographic data and cloud-managed network experience years shows in Table 1. IT professional users have more participants than the IT vendors or resellers, and the majority of both groups have experiences in the technology about 1-3 years.

Table 1. Overall participants' demographic data and cloud-managed network experiences

\begin{tabular}{|l|c|c|}
\hline Demographic Data & IT professional users & Vendors \\
\hline Participants & 158 & 77 \\
\hline Job titles & IT professional/Engineer, 58\% & IT professional/Engineer, 60\% \\
& Supervisor, junior / senior manager, 10\% & Supervisor, junior / senior manager, 3\% \\
& Student 7\% & Sale \& Marketing, 20\% \\
& Professor, 3\% & Student 3\% \\
& Sales or Marketing 11\% & Professor, 1\% \\
& Consulting 3\% & Consulting 4\% \\
& Executive /CIO/CTO/VP/CEO 2\% & Executive /CIO/CTO/VP/CEO 7\% \\
Oloud-managed & Other 6\% & Other 2\% \\
network experiences & $1-3$ years, 44.3\% & $1-3$ years, 35.1\% \\
(Years) & $4-7$ years, 15.2\% & $4-7$ years, 26\% \\
& $8-15$ years, 7.6\% & $8-15$ years, 18.2\% \\
& Above 16 years, 6\% & Above 16 years, 13\% \\
\hline
\end{tabular}

Table 2 presents the one-way analysis of variance (ANOVA) for a series of the statements on the five factors, which were responded to by 235 participants with 158 from the IT professional users and 77 from the vendors/resellers. The findings show that the mean values of the five factors of vendor/resellers are greater than the mean values of IT professional. This suggests that vendors/resellers perceive differ or agree more than IT professional users in the same direction.

Table 2 indicates that the different perceptions based on the P-value reported less than a level of significance $\alpha=$ 0.05 . As a result, there are the twenty-seven statements with the significant differences. There is only one statement that respondents perceive a similar way in the security factor in term of: "I must know a security compliance before making a decision to use cloud-managed networks." Table 3 shows that the IT professional users rank the important factors in adopting cloud-managed network technology, from most important to least important, as complexity, cost savings, job performance, compatibility, and security respectively. While, vendors/resellers rank the important factors, from most important to least important, as cost savings, complexity, job performance, security, and compatibility respectively. 


\section{Issues in Information Systems}

Volume 20, Issue 1, pp. 49-59, 2019

Table 2. Mean values of the five key factors.

\begin{tabular}{|c|c|c|c|c|}
\hline Key factors & Perception statements & $\begin{array}{l}\text { IT } \\
\text { users } \\
\text { (Mean) }\end{array}$ & $\begin{array}{l}\text { Vendors } \\
\text { (Mean) }\end{array}$ & $\begin{array}{l}\text { P-Value } \\
\text { Sig. } \\
(<0.05)\end{array}$ \\
\hline \multirow{6}{*}{ Complexity } & $\begin{array}{l}\text { 1. My interaction with a cloud managed network is clear and } \\
\text { understandable. }\end{array}$ & 3.48 & 3.93 & 0.000029 \\
\hline & 2. Learning to operate a cloud managed network device is easy for me. & 3.61 & 3.99 & 0.000648 \\
\hline & 3. I have no difficulty understanding and using cloud managed networks. & 3.59 & 4.00 & 0.000375 \\
\hline & 4. I rarely become confused when I use cloud managed network devices. & 3.4 & 3.96 & 0.000002 \\
\hline & 5. Overall, a cloud managed network is easy to use. & 3.58 & 4.04 & 0.000012 \\
\hline & $\begin{array}{l}\text { 6. Complexity is the key factor that influences me to adopt cloud managed } \\
\text { networks. }\end{array}$ & 3.33 & 3.95 & 0.000003 \\
\hline \multirow{7}{*}{ Security } & $\begin{array}{l}\text { 1. Data security is the biggest challenge for me to use cloud managed } \\
\text { networks devices. }\end{array}$ & 3.72 & 3.91 & 0.039968 \\
\hline & $\begin{array}{l}\text { 2. I must know a security compliance before making a decision to use } \\
\text { cloud managed networks. }\end{array}$ & 3.96 & 4.17 & $\mathbf{0 . 0 5 8 3 7 9}$ \\
\hline & $\begin{array}{l}\text { 3. I trust security services that are provided from vendors' cloud managed } \\
\text { networks. }\end{array}$ & 3.28 & 3.86 & 0.000011 \\
\hline & 4. I recommend friends to adopt cloud managed networks technology. & 3.43 & 4.00 & 0.000001 \\
\hline & $\begin{array}{l}\text { 5. Using cloud managed networks in my work place is safer than using a } \\
\text { traditional system. }\end{array}$ & 3.2 & 3.79 & 0.000018 \\
\hline & $\begin{array}{l}\text { 6. With a cloud managed network, vendor provides enough security and } \\
\text { guarantee data stored safety in the cloud. }\end{array}$ & 3.32 & 3.86 & 0.000007 \\
\hline & $\begin{array}{l}\text { 7. Security is the key factor that influences me to adopt cloud managed } \\
\text { networks. }\end{array}$ & 4.07 & 3.62 & 0.000526 \\
\hline \multirow{4}{*}{ Compatibility } & $\begin{array}{l}\text { 1. I feel that cloud managed network can work with existing network } \\
\text { devices. }\end{array}$ & 3.75 & 4.00 & 0.019742 \\
\hline & $\begin{array}{l}\text { 2. I think that cloud managed network devices are compatible with my } \\
\text { existing network devices. }\end{array}$ & 3.64 & 4.00 & 0.001410 \\
\hline & 3. Using a cloud managed network supports my ability to complete a task. & 3.55 & 3.99 & 0.000154 \\
\hline & $\begin{array}{l}\text { 4. Compatibility is the key factor that influences me to adopt cloud } \\
\text { managed networks. }\end{array}$ & 3.67 & 3.99 & 0.007995 \\
\hline \multirow{7}{*}{$\begin{array}{l}\text { Job } \\
\text { performance }\end{array}$} & 1. Cloud managed network enables me to accomplish tasks more quickly. & 3.59 & 4.05 & 0.000038 \\
\hline & 2. Cloud managed network has improved my quality of work. & 3.45 & 3.82 & 0.001590 \\
\hline & 3. Cloud managed network makes it easier to do my job. & 3.55 & 3.97 & 0.000295 \\
\hline & 4. Cloud managed network has improved my productivity. & 3.5 & 3.96 & 0.000076 \\
\hline & 5. Cloud managed network gives me greater control over my job. & 3.41 & 3.89 & 0.000010 \\
\hline & 6. Cloud managed networks enhances my effectiveness on the job. & 3.48 & 3.91 & 0.000053 \\
\hline & $\begin{array}{l}\text { 7. Job Performance is the key factor that influences me to adopt cloud } \\
\text { managed networks. }\end{array}$ & 3.46 & 3.95 & 0.000055 \\
\hline \multirow{4}{*}{ Cost saving } & $\begin{array}{l}\text { 1. Adopting the cloud managed networks technology such WiFi helps to } \\
\text { reduce IT costs. }\end{array}$ & 3.49 & 3.96 & 0.000038 \\
\hline & $\begin{array}{l}\text { 2. Many cloud managed network vendors offer free network management } \\
\text { applications to manage the cloud network devices. }\end{array}$ & 3.43 & 3.93 & 0.000006 \\
\hline & 3. Using cloud managed networks is more costly than traditional systems. & 3.18 & 3.76 & 0.000013 \\
\hline & $\begin{array}{l}\text { 4. Cost saving is the key factor that influences me to adopt cloud managed } \\
\text { networks. }\end{array}$ & 3.55 & 3.93 & 0.001020 \\
\hline
\end{tabular}


Table 3. Ranking importance of Complexity, Compatibility, Security, Job Performance, and Cost-saving factors for IT professional users and IT vendors / resellers

\begin{tabular}{lll}
\hline $\begin{array}{l}\text { Ranking Important influential factors in adopting } \\
\text { the cloud-managed networks } \\
\text { (Ranking order from the most importance to the }\end{array}$ & $\begin{array}{l}\text { IT professional users } \\
\text { (Ranking factors) }\end{array}$ & $\begin{array}{l}\text { IT vendor / resellers } \\
\text { (Ranking factors) }\end{array}$ \\
\hline 1 & Complexity & Cost-saving \\
2 & Cost-saving & Complexity \\
3 & Job Performance & Job Performance \\
4 & Compatibility & Security \\
5 & Security & Compatibility \\
\hline
\end{tabular}

\section{DISCUSSION}

The study explores five variables including complexity, compatibility, cost savings, security, and job performance and finds the differences in the perceptions and the rankings of the important factors. The following sections describe implication and the study findings and how those findings correspond to the research questions.

Technology acceptance model (TAM), Diffusion of Innovation Theory (DOIT), and other studies were used as guidelines to identify the five factors and to develop the theoretical framework of this study. The results were shown that the theoretical framework was validated and verified that the five factors were the key concerns for IT professional users and vendors when they use cloud-managed network technology.

The overall study is noteworthy for academics and practitioners looking to provide the right strategy for IT adoption frameworks, product development, or technology adoption to fit into their organization. From an academic researcher's view, the results indicate the ranking of the importance of influential factors that have an effect on some aspect of technology diffusion. Complexity and cost savings are the most important key factors for cloud technology adoption. The findings suggests that researchers should account for complexity and cost savings variables to some extent in technology adoption frameworks. Security aspects were addressed and enhanced in the early stages of cloud technology and have continued evolving and improving. Therefore the security factor was not really a concern for cloud adoption today.

Despite the fact that the new technology (e.g. cloud-managed networking) emerged from the original or primary technology (e.g. cloud computing) and did not disrupt that technology, the key factors in technology adoption do not have the same degree of priority as were found in the primary or original technology.

From a practitioner's view, although users and vendors perceived different important ranking factors, they are in the same positive direction of cloud technology adoption. Managers should manage the different viewpoints from their users and vendors by validating and verifying to make sure that the technology is not creating a hard time for implementing, operating, and supporting it. As well cost savings must be considered first as the primary benefit for organizations. Complexity does not only in product development process, but also in training packages deliverable from vendors to customers. Managers need to ensure that both users and vendors are on the same page and technology adoption projects are executed effectively and smoothly to accomplish the goal.

\section{RQ1: What are the users and vendors' perception on the adoption of cloud managed networks in terms of complexity, compatibility, cost-saving, security and job performance factors?}

The findings showed that the five factors: complexity, compatibility, cost savings, security, and job performance were important for both IT professional users and vendors/resellers groups. The overall mean of the five factors in Table 2, reported that the vendors/resellers have mean values greater than IT professional users. This can be explained that vendors/resellers need to ensure that their products meet the customers' requirements, needs, and expectations. Thus, vendors strongly agreed that the five key factors must be addressed and included in their product 
development for the benefit of customers. These five key factors are important for cloud-managed networks adoption, because the technology offers simplicity, the speed of implementation, cost saving and effective operation. Vendors have to make sure that they develop cloud-managed network products with cost-saving, complexity reduction, and benefits to customers. On the other hand, customers want to make sure that the price is right with no complexity and compatible to their existing system, deliverable job performance, and better cost savings with more secured to protect the data in the cloud.

\section{RQ2: What is the difference between the users and vendors' perception of the five factors?}

The findings showed that perceptions difference between IT professional users and vendors/resellers in the five factors. This result was consist with previous studies (Liu \& Yuliani, 2016; Gorla \& Somers, 2014) that found that there were potential perception inconsistency between the client and the vendor for IT projects. The different perceptions indicated that vendors/resellers agreed more on the five factors than IT professional users on these five factors in the same direction.

Complexity: Vendors/resellers usually get to know their products well before selling to customers. The cloudmanaged network technology is still in the early stages of adoption as the majority of IT professional users have less experience of 1-3 years for cloud-managed network technology. Therefore, vendors/resellers must make sure that the cloud-managed products are easy to use for the customers.

Compatibility: The cloud-managed networks products must be able to integrate or work well with the existing systems in order to convince the customers to use the technology. Because there are many different IT networking devices with different vendors used in organizations, the vendors must make sure that their cloud networking devices are compatible with the existing devices.

Security: Data security is one of the biggest challenges when using cloud technology. Vendors have to deal with consumers' discomfort with security aspects concerning confidentiality, integrity, availability and trust. To build trust, I believe that vendors must guarantee their cloud services having industry security standard, compliance, and audited by a $3^{\text {rd }}$ party, to be more secured anytime and anywhere in order for customers to access their information and assets.

Job performance: I believe that cloud-managed networks technology provide the same quality of work as same as the exiting networking devices on-premised in organization, because the main functionalities of IT networking devices still remain the same, such as routers, switches, firewalls, and wireless or Wi-Fi, no matter how the devices will be used either on-premises or in-cloud. Therefore, job performance plays in a role that does not quite important comparing to complexity and cost saving factors.

Cost savings: Vendors/resellers identified cost savings as the top priority of IT. This result was consisted with previous studies (Luftman \& Ben-Zvi, 2009; Luftman et al., 2013) that cost savings is the top concern of IT organizations when making decisions about when to adopt the new technology. If the cloud technology devices are cheaper than the on-premises networking devices, then there is high probability that users will adopt the technology. Therefore, vendors are aware that it is difficult to deliver innovative technology if the cost is higher. Cost savings is one of the market forces of commercial innovation, which concern to the price (Kline \& Rosenberg, 1986).

\section{RQ3: What is the ranking of the importance of five factors for the IT users and vendors?}

Complexity: IT professional users found complexity to be the most important factor in adopting cloud-managed networks technology. The IT professional users don't want to deal with cloud network devices that are difficult to operate and manage. It is reasonable to believe that this is why the end-users voted the complexity factor as the highest priority. The result was consistent with the perceived attributes of DOIT, which finds that complexity was one of the important factors in the decision process (Rogers, 1962), and can be confirmed with TAM, which finds that ease of use is one of the primary influential factors in users' attitudes about adopting the new technology (Davis, 1989). Cost saving: On the other hand, the vendors/resellers rank cost saving as the most important factor. The cost savings factor was the strongest influence on decision making for the adoption of the technology. The result was consistent with prior studies, such as those of Luftman and Ben-Zvi, 2009; Luftman et al., 2013; Cisco, 2016; Aruba, 2016; Theophilus, Aditya, Anees \& Sambit, 2011; Premkumar and Ramamurthy, 1995; Rogers, 1962; and Rob et al., 2009. The cost savings factor is the most common factor that influenced decision makers to adopt cloud networks, which is also supported by previous studies such as Premkumar and Ramamurthy, 1995. Security: It is interesting that the security became the least important factor for IT professional users when deciding whether to adopt cloud-managed networks. The IT profession users do not believe that data security is the biggest challenge 
to use cloud managed networks devices. It was unexpected finding that security was identified as the least important factor for cloud-managed network technology. One way that it can be explained is that cloud-managed network technology emerged after cloud computing technology was adopted based on the cloud revolution. Therefore, cloud computing has already been proven to have enough security and guaranteed data storage safety, and users feel comfortable with cloud technology including cloud-managed network technology.

This result was not consistent with prior studies of related technology and cloud computing adoption, such as those done by Subashini \& Kavitha, 2011; Clavister, 2009; Cloud Security Alliance, 2010; and Alfifi, 2015, which stated that security was a great concern for users of cloud services among different organizations. Vendors/resellers perceive similarly to IT users and voted security as the second least important factor for cloud-managed network adoption. Compatibility: Additionally, the findings showed that the compatibility factor was the least important factor for the vendors/resellers in adopting cloud-managed network technology. The vendors perceived cloudmanaged network devices as providing the same results to get the jobs done as the on-premises networking devices. So, cloud-managed network devices are compatible. This result was not consistent with prior studies of cloud computing adoption (Cooper and Zmud, 1990; Wang et al., 2010), which stated that compatibility was considered an essential factor for innovation adoption. Job performance: Based on the data analysis, IT professional users and vendors/resellers have the same ranking for the job performance factor as a factor with neutral degree of importance when compared to other factors. Davis (1989) asserted that perceived usefulness is the degree to which a person believes that a particular information system would enhance his or her job performance by reducing the time to accomplish a task. Other studies of relative technology adoption such as cloud computing (Childers, Carr, Peck, \& Carson, 2001; Trinh, 2014; Pikkarainen, Pikkarainen, Karjaluoto, \& Pahnila, 2004; and Ibrahim, 2014), showed that perceived usefulness of job performance was strongly significant and had a positive relationship with users' intention to adopt cloud computing solutions. However, the result was not the same priority as those previous studies.

\section{LIMITATION}

This field research used survey questionnaires to collect data from IT people of two groups: professional users and vendors/resellers. The research was limited to the viewpoints of IT professional engineers that could lead to biases in the perceptions of the factors considered when adopting cloud-managed network technology. Since the majority of participants in this study were IT engineers, other employees, who use IT or make decisions, could have different perceptions or motivations concerning cloud networking technology.

Another limitation of this study was only focusing on five factors as the important factors. There are other external or internal factors that could influence IT people to use the technology, such as legalities, organizational culture, decision-making policies, partnership, and service level agreements (SLA).

The result also reflects a noticeable imbalanced between the two groups. There are 158 IT professional users and 77 vendors/resellers, which may introduce discrepancies in the responses to the survey. The participants included in this study are mostly in the United States, so the generalizability of the conclusions is limited to the work scopes performed and the perceptions in similar societies.

\section{FUTURE RESEARCH}

This field research provided the important findings of IT professional users and vendors'/resellers' perceptions on the five key factors. The results of this study have identified differences in the perceptions and the ranking of important factors. However, there are several areas that appeared to be good topics to discuss but were not within the scope of the original study. Other key factor influences on cloud-managed network adoption should be considered in future studies, such as organizational culture, policy, the relationship between clients and vendors, the difference between different type of customers such as small, medium or large, or the relationship between managers and IT professionals. 


\section{Issues in Information Systems}

Volume 20, Issue 1, pp. 49-59, 2019

Socio-linguistic research has shown that gender is a fundamental aspect of culture: men tend to focus discourse on hierarchy and independence, while women focus on intimacy and solidarity (Gefen \& Straub, 1997). Thus, studies have suggested that researchers should include gender factor in adopting technology.

Cloud computing and networking are continually changing and producing security challenges, and we see the need to continue to integrate these activities. Some researchers suggest that the nature of cloud technology in general brings many unforeseen changes. Working closely with industry and customers we can expect to positively influence cloud-associated risk management (Pearson, S., \& Yee, G. 2013). Future studies can also focus on the risk management of cloud-managed network technology adoption.

\section{CONCLUSION}

This study confirmed the framework for this research in Figure 1, that the five factors: complexity, compatibility, security, job performance, and cost savings, were the key important factors for cloud-managed network technology adoption based on the perceptions of IT professional users and vendors/resellers. The vendors/resellers have more concerns or agreed more on the five factors than IT professional users in the same direction. Complexity and Cost savings were the most important influential factors for IT professional users and vendors/resellers respectively. This result confirmed with the same results of previous studies and with the different priority factor from TAM, which defines perceived usefulness and perceived ease of use as the primary influential factors.

This study contributes to the body of IT technology knowledge by providing empirical evidence of IT users' and vendors' perceptions on the important factors in adopting cloud network technology: complexity, compatibility, security, job performance, and cost savings. The result of this study is to identify differences in the perceptions and how IT professional users and vendors rank the importance of the factors. This study might help IT practitioners in understanding the perceptions and the ranking of important factors for both sides, IT professional users and vendors/resellers; provide important results for product development to improve on vendor's marketing strategies; and enhance decision making concerning adopting cloud network technology for IT users.

\section{REFERENCES}

Alfifi, F. (2015). Factors Influencing the Adoption of Cloud Computing by CIOs and Decision Makers in Higher Education Institutions (Doctoral Dissertation). Retrieved from https://reddog.rmu.edu:3479/pqdtlocal1006577/docview/1730289702/D57EAF105BDE4112PQ/1?accounti $\mathrm{d}=28365$

Aruba. (2016). Aruba central management and services in the cloud. Retrieved from http://www.arubanetworks.com/products/networking/management/central/.

Boroujerdi, M. M., \& Nazem, S. (2009). Cloud computing: Changing cogitation about computing. World Academy of Science, Engineering and Technology.

Childers, T. L., Carr, C. L., Peck, J., \& Carson, S. (2001). Hedonic and utilitarian motivations for online retail shopping behavior. Journal of retailing, 77(4), 511-535.

Cisco. (2016). Cloud networking architecture. Retrieved from https://meraki.cisco.com/products/architecture/

Clavister. (2009). Security in the cloud, Clavister White Paper. Retrieved from http://www.itwire.nu/members/cla69/attachments/CLA_WP_SECURITY_IN_THE_CLOUD.pdfS.

Cloud Security Alliance (CSA). (2010). Retrieved from http://www.cloudsecurityalliance.org.

Cooper, R.B., \& Zmud, R.W. (1990). Information technology implementation research: a technological diffusion approach. Management Science, 36, 123-39. 
Creswell, J. W. (2009). Research design: Qualitative, quantitative, and mixed methods approaches (3rd). Los Angeles, CA: Sage Publications.

Davis, F. D. (1989). Perceived usefulness, perceived ease of use, and user acceptance of information technology. MIS Quarterly, 13 (3), 319-340.

Duan, Q., Yan, Y., \& Vasilakos, A. V. (2012). A survey on service-oriented network virtualization toward convergence of networking and cloud computing. IEEE Transactions on Network and Service Management, 9(4), 373-392.

Gefen, D., \& Straub, D. W. (2000). The relative importance of perceived ease-of-use in IS adoption: A study of ecommerce adoption. Journal of the Association for Information Systems, 1(8), 1-30.

Gefen, D., \& Straub, D. W. (1997). Gender differences in the perception and use of e-mail: An extension to the Technology Acceptance Model. MIS Quarterly, 21(4), pp.389

Gorla, N., \& Somers, T. M. (2014). The impact of IT outsourcing on information systems success. Information \& Management, 51(3), 320 - 335.

Hoving, R. (2007). Information technology leadership challenges - Past, present, and future. Information Systems Management, 24(1), 147-153.

Ibrahim, H.M. (2014). Assessing cloud computing adoption by IT professionals in small business using the technology acceptance model. ProQuest Dissertations Publishing. 3579718.

Johnson, J., Boucher, K.D., Connors, K., \& Robinson, J. (2001). Collaboration: Development \& Management Collaborating on Project Success.

Keil, M., Tiwana, A., \& Bush, A. (2002). Reconciling user and project manager perceptions of IT project risk: A Delphi study. Information Systems Journal, 12(2), 103 - 119.

Kline, S.J., \& Rosenberg, N. (1986): An overview of innovation. The positive sum strategy: Harnessing technology for economic growth, Washington, DC. National Academy Press, 275-306.

Liu, J. Y., \& Yuliani, A. R. (2016). Differences between clients' and vendors' perceptions of IT outsourcing risks: Project partnering as the mitigation approach. Project Management Journal, 47(1), 45-58.

Luftman, J., \& Ben-Zvi, T. (2009). Key issues for IT executives 2009: Difficult economy's impact on IT. MIS Quarterly Executive, 9(1), 49-58.

Luftman, J., Zadeh, H.S., Derksen, B., Santana, M., Rigoni, E.H. \& Huang, D. (2013). Key information technology management issues 2012-2013: An international study, Journal of Information Technology, 28(4), 354366.

McCloskey, D. (2004). Evaluating electronic commerce acceptance with the technology acceptance model. The Journal of Computer Information Systems, 44(2).

Middleton, C., \& Potter, A. 2008. "Is it good to share? A case study of the FON and Meraki approaches to broadband provision", ITS Biennal Conference, Montreal.

Pearson, S., \& Yee, G. (2013). Privacy and Security for Cloud Computing. Springer, Series on Computer Communications and Networks. 
Pikkarainen, T., Pikkarainen, K., Karjaluoto, H., \& Pahnila, S. (2004). Consumer acceptance of online banking: An extension of the technology acceptance model. Internet Research, 14(3), 224-235.

Premkumar, G., \& Ramamurthy, K. (1995). The role of inter-organizational and organizational factors on the decision mode for adoption of inter-organizational systems. Decision Sciences, 26(3), 303-336.

Premkumar, G., \& Roberts, M. (1999). Adoption of new information technologies in rural small businesses. OMEGA, The International Journal of Management Science, 27, 467-484.

Rob, S., Glen, G., Kok-Kiong, Y., Guido, A., Martin, C., Nick, M., \& Guru, P. (2009). Flow visor: A network virtualization layer. Deutsche Telekom Inc. R\&D Lab, Stanford University, Nicira Networks.

Rogers, E. M. (1962). Diffusion of innovations. New York: Free Press.

SDxCentral. (2012). What is cloud networking or cloud based networking? Retrieved from https://www.sdxcentral.com/cloud/definitions/all-about-cloud-networking/

Subashini, S., \& Kavitha, V. (2011). A survey on security issues in service delivery models of cloud computing. Journal of Network and Computer Applications, 34(1), 1-11

Theophilus, B., Aditya, A., Anees, S., \& Sambit, S. (2011). CloudNaaS: A cloud networking platform for enterprise applications. In Proc. SOCC.

Trinh, M.T. (2014). Investigating acceptance of cloud computing in the United States health care industry. ProQuest Dissertations Publishing, 3634485.

Van Teijlingen ER., \& Hundley, V. (2001). The Importance of Pilot Studies. Social Research Update. Retrieved from http://sru.soc.surrey.ac.uk/SRU35.html

Venkatesh, V.,\& F. D. Davis. (1996). A model of the antecedents of perceived ease of use: Development and test. A Journal of the Decision Science Institute, 27, 451-481.

Wang, Y.M., Wang, Y.S., \& Yang, Y.F. (2010). Understanding the determinants of RFID adoption in the manufacturing industry. Technological Forecasting \& Social Change, 77, 803-15.

Yap, K., Sherwood, R., Kobayashi, M., Handigol, N., Huang, T., Chan, M., McKeown,N., \& Parulkar, G. (2009). Blueprint for introducing innovation into the wireless networks we use every day. Retrieved from http://openflowswitch.org/downloads/technicalreports/openflow-tr-2009-3-openflowwireless.pdf.

Yu, J.C., Liu, C., \& Yao, J. E. (2003). Technology acceptance model for wireless. Internet. Internet Research, 13(3), 206-222. 